\title{
Article \\ Adsorption Properties of Soft Hydrophobically Functionalized PSS/MA Polyelectrolytes
}

\author{
Ewelina Jarek $^{1}$, Zofia Krasińska-Krawet ${ }^{1}$, Tomasz Kruk ${ }^{1}$, Łukasz Lamch $^{2}{ }^{\circledR}$, Sylwia Ronka ${ }^{3}{ }^{(0}$, \\ Kazimiera A. Wilk ${ }^{2, * \mathbb{D}}$ and Piotr Warszyński ${ }^{1, * \mathbb{D}}$ \\ 1 Jerzy Haber Institute of Catalysis and Surface Chemistry, Polish Academy of Sciences, Niezapominajek 8, \\ 30-239 Kraków, Poland; ewelina.jarek@ikifp.edu.pl (E.J.); nckrasin@cyf-kr.edu.pl (Z.K.-K.); \\ tomasz.kruk@ikifp.edu.pl (T.K.) \\ 2 Department of Engineering and Technology of Chemical Processes, Faculty of Chemistry, Wrocław University \\ of Science and Technology, Wybrzeże Wyspiańskiego 27, 50-370 Wrocław, Poland; lukasz.lamch@pwr.edu.pl \\ 3 Department of Engineering and Technology of Polymers, Faculty of Chemistry, Wrocław University of \\ Science and Technology, Wybrzeże Wyspiańskiego 27, 50-370 Wrocław, Poland; sylwia.ronka@pwr.edu.pl \\ * Correspondence: kazimiera.wilk@pwr.edu.pl (K.A.W.); piotr.warszynski@ikifp.edu.pl (P.W.)
}

Citation: Jarek, E.; Krasińska-Krawet, Z.; Kruk, T.; Lamch, Ł.; Ronka, S.; Wilk, K.A.; Warszyński, P. Adsorption Properties of Soft Hydrophobically Functionalized PSS/MA Polyelectrolytes. Colloids Interfaces 2021, 5, 3. https://doi.org/10.3390/ colloids5010003

Received: 13 November 2020 Accepted: 12 January 2021 Published: 14 January 2021

Publisher's Note: MDPI stays neutral with regard to jurisdictional clai$\mathrm{ms}$ in published maps and institutional affiliations.

Copyright: (C) 2021 by the authors. Licensee MDPI, Basel, Switzerland. This article is an open access article distributed under the terms and conditions of the Creative Commons Attribution (CC BY) license (https:// creativecommons.org/licenses/by/ $4.0 /)$.

\begin{abstract}
We investigated the adsorption properties of the newly synthesized, hydrophobically functionalized polyelectrolyte (HF-PE), poly(4-styrenesulfonic-co-maleic acid) copolymer (PSS/MA). The hydrophobic alkyl side chains $\left(\mathrm{C}_{12}\right.$ or $\left.\mathrm{C}_{16}\right)$ were incorporated into the polyelectrolyte backbone via the labile amid linker to obtain the soft HF-PE product with the assumed amount of $15 \%$ and $40 \%$ degree of grafting for every length of the alkyl chain, i.e., PSS/MA-g- $\mathrm{C}_{12} \mathrm{NH}_{2}(15 \%$ or $40 \%)$ as well as PSS/MA-g- $\mathrm{C}_{16} \mathrm{NH}_{2}(15 \%$ or $40 \%)$. In the present contribution, we determined both the effect of grafting density and the length of alkyl chain on adsorption at water/air and water/decane interfaces, as well as on top of the polyelectrolyte multilayer (PEM) deposited on a solid surface. The dependence of the interfacial tension on copolymer concentration was investigated by the pendant drop method, while the adsorption at solid surface coated by poly(diallyldimethylammonium chloride)/poly(styrene sulphonate) PEM by the quartz crystal microbalance with dissipation (QCMD), attenuated total reflection Fourier transform infrared spectroscopy (FTIR-ATR) and contact angle analysis. We found that surface activity of the hydrophobized copolymer was practically independent of the grafting ratio for $\mathrm{C}_{16}$ side chains, whereas, for $\mathrm{C}_{12}$, the copolymer with a lower grafting ratio seemed to be more surface active. The results of QCM-D and FTIR-ATR experiments confirmed the adsorption of hydrophobized copolymer at PEM along with the modification of water structure at the interface. Finally, it can be concluded that the hydrophobically modified PSS/MA can be successfully applied either as the efficacious emulsifier for the formation of (nano)emulsions for further active substances encapsulation using the sequential adsorption method or as one of the convenient building blocks for the surface modification materials.
\end{abstract}

Keywords: hydrophobized polyelectrolyte; adsorption; interfacial tension; wetting; water structure

\section{Introduction}

Nowadays, polyelectrolytes as classical soft-matter materials are of particular interest because they can modify many substrates at any interface, functionalize them, and convert them into various compatible forms with many solvents. Particularly they exert profound effects on colloidal stability for many biomedical purposes and engineered surfaces and can be applied at biointerfaces for many pharmaceutical or cosmetic applications [1-4]. Moreover, they can be designed as responsive polymer materials, playing an increasingly important part in a diverse range of applications, such as drug delivery, diagnostics, tissue engineering, and 'smart' optical systems, as well as biosensors, microelectromechanical systems, coatings, textiles and much more [5]. The associative behavior of oppositely charged 
polyelectrolytes is a phenomenon relevant to many biological processes and many synthetic applications [6]. The charge distribution, hydrogen bonding, type and distribution of hydrophobic moieties, and steric effects dictate the shape, conformation, and ultimately the function of complex biomacromolecules. In engineered applications, the polyelectrolyte complexes can form micelles, gels, and coatings. Polyelectrolytes at interfaces are a classical field of soft-matter physics. They are of particular interest because they can modify substrates and turn them functional or compatible with particular solvents. One of the most promising techniques involving polyelectrolyte complexation is their sequential adsorption at macroscopic and colloidal objects for the purpose of surface modification, biocompatibility, encapsulation, or the regulation of the encapsulated cargo release [7-13]. In all of these contexts, the dynamic ionic bonds formed between oppositely charged ions dictate the polyelectrolyte assembly's responsiveness and properties [14]. Macromolecules have profound effects on colloidal stability. They can act as either stabilizers (steric stabilization) or destabilizers of colloids by bridging or depletion flocculation. The stabilizing effect of adsorbed polymers depends on their structure and the dynamics of the system [15].

Hydrophobically modified polyelectrolytes are water-soluble polyelectrolytes (PE) that usually contain a limited number of hydrophobic groups incorporated into a hydrophilic polymer backbone. They self-associate in aqueous solutions forming compact conformations similar to those of surfactant or soap micelles; therefore, they are often referred to as "polysoaps" [16]. In dilute aqueous solutions polysoaps self-organize into intramolecular micelles above a certain threshold content of hydrophobic moieties. Shapes of these micelles and their numbers per chain are determined by a fine interplay between electrostatic and hydrophobic interactions [17-19]. Polysoaps in semidilute or concentrated solutions form intermolecular aggregates. At high polymer and salt concentrations, the intermolecular associations may lead to a phase separation [20,21]. The amphiphilic structure of hydrophobically modified polyelectrolyte provides a surfactant-like behavior and desirable rheological characteristics in aqueous polymer solutions and dispersions. Above a specific polymer concentration, the hydrophobic units associate together, and the solution viscosity increases significantly. However, they exhibit shear-thinning characteristics, making these materials valuable in paint, personal care, enhanced oil recovery and other applications. Many of these polymers have been commercialized, including hydrophobically modified hydroxyethyl celluloses (HMHECs), hydrophobically modified ethoxylated urethanes (HEURs), and hydrophobically modified alkali-swellable emulsions (HASEs) [22]. Since hydrophobized polyelectrolytes can self-aggregate in aqueous media and form lipophilic microdomains, which are much more stable than micelles made of amphiphilic low molecular weight surfactants, they can be used as nanocarriers for hydrophobic cargo [23-25]; however, the amounts of drug incorporated in the microdomains is low. On the other hand, formation of intermolecular aggregates with larger domains is hard to control. Alternatively, the hydrophobized polyelectrolytes can be used for the formation of nanoemulsions and as an anchoring layer for further encapsulation by the sequential adsorption of polyelectrolytes [26].

The molecular structure of poly(4-styrenesulfonic-co-maleic acid) copolymer (PSS/MA) contains strongly acidic sulfonate and weakly acidic maleic acid groups simultaneously present in the polymer chain allowing for electrostatic interaction via $\mathrm{pH}$ and ionic strength response $[27,28]$. Moreover, the carboxyl group presence offers the option of conjugating proteins [29] or other molecules to create new functions for polyelectrolytes. For example, PSS/MA was used for the formation of polyelectrolyte multilayers for the low-humidity sensors [30], whereas Maza et al. described a pH-controlled ion-rectifying system employing polyelectrolyte multilayers assembled from PSS/MA, alternately deposited with poly(diallyl dimethylammonium chloride) [31].

As a continuation of our studies on soft HF-PEs $[6,20]$ in the present contribution, we report our findings on adsorption behavior of newly synthesized, hydrophobically functionalized polyelectrolyte (HF-PE), i.e., decorated along its backbone with alkyl chains $\left(C_{12}\right.$ or $\left.C_{16}\right)$ via the labile amid linker with the assumed amount of $15 \%$ and $40 \%$ degree 
of grafting for every length of alkyl chain (for the synthesis procedure see the previous report [6]). While the literature concerning grafting polymers is abundant [2,32], the reports on hydrophobically modified grafted PSS/MA are limited [6]. The synthesized amphiphilic polyelectrolytes were found to reveal excellent aqueous solubility as well as structure and concentration dependent self-association behavior. Surface tension at aqueous polymer solution/air interface and interfacial tension at the solution/decane were determined using the pendant drop shape analysis method. The quartz crystal microbalance with dissipation analysis (QCM-D) technique provided mass and viscoelastic properties of films adsorbed on quartz crystal sensors' surface. Fourier transform infrared spectroscopy (FTIR) in the attenuated total reflectance (ATR) mode was applied for the in-situ observation of the polyelectrolyte multilayer (PEM) assembly and adsorption of hydrophobically modified PSS $/$ MA-g- $\mathrm{C}_{\mathrm{n}} \mathrm{NH}_{2}(\mathrm{n}=12,16$ the grafting ratio $=15 \%, 40 \%)$. We correlated the observed changes in the interfacial water structure with the hydrophobicity of polymer deposited as a terminating PEM layer.

\section{Materials and Methods}

The hydrophobized poly(4-styrenesulfonic-co-maleic acid) (PSS/MA) with side alkyl chains with twelve and sixteen carbon atoms attached to the backbone via secondary amide bonds were recently synthesized. The polymer precursor poly(4-styrenesulfonic-co-maleic acid) was purchased from Sigma-Aldrich (average $\mathrm{M}_{\mathrm{W}} \sim 20,000 \mathrm{Da}, 1: 1$ 4-styrenesulfonic acid:maleic acid mole ratio, viscosity $30 \mathrm{cP}\left(30 \%\right.$ in $\left.\mathrm{H}_{2} \mathrm{O}\right)$, density $0.94 \mathrm{~g} / \mathrm{mol}$ at $\left.25^{\circ} \mathrm{C}\right)$. We obtained PSS/MA polyelectrolytes with $15 \%$ and $40 \%$ degree of grafting for every length of alkyl chain, i.e., PSS / MA-g- $\mathrm{C}_{12} \mathrm{NH}_{2}(15 \%)$, PSS/MA-g- $\mathrm{C}_{12} \mathrm{NH}_{2}(40 \%)$, PSS/MAg- $\mathrm{C}_{16} \mathrm{NH}_{2}(15 \%)$ and PSS/MA-g- $\mathrm{C}_{16} \mathrm{NH}_{2}(40 \%)$. The degree of grafting was calculated as the mol \% content of $\mathrm{C}_{\mathrm{x}}$ side chains with respect to maleic acid groups, i.e., it indicates percent of carboxylic acid groups with chemically attached alkyl chain. The calculated grafting densities (the number of pendant $C_{x}$ chains per copolymer) were equal to 18.6 (for PSS/MAg- $\mathrm{C}_{12} \mathrm{NH}_{2}(15 \%)$ and PSS/MA-g- $\mathrm{C}_{16} \mathrm{NH}_{2}(15 \%)$ ) and 49.6 (for PSS/MA-g-C ${ }_{12} \mathrm{NH}_{2}(40 \%)$ and PSS/MA-g- $\left.\mathrm{C}_{16} \mathrm{NH}_{2}(40 \%)\right)$. The general procedure for the synthesis of those functionalized copolymers was described in our previous paper [6]. Figure 1 illustrates the structure of synthesized polymers. The detailed synthesis route as well as IF-IR and ${ }^{1} \mathrm{H}$ NMR spectra (Figures S1-S4) of resulting copolymers are given in ESI.

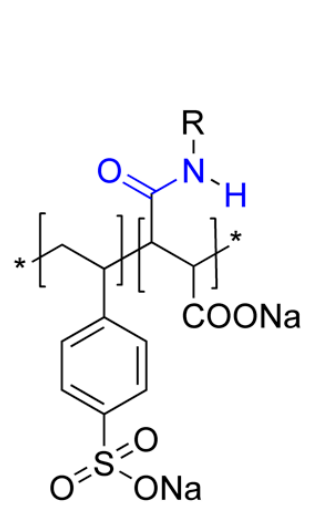

$$
\begin{array}{lcc}
\mathrm{R}= & \text { \% hydrophobization } & \text { Abbreviation } \\
\cline { 2 - 3 } \mathrm{C}_{12} \mathrm{H}_{25} & 15 \% & \text { PSS/MA-g- }{ }_{12} \mathrm{NH}_{2}(15 \%) \\
\cline { 2 - 3 } & 40 \% & \text { PSS/MA-g-C }{ }_{12} \mathrm{NH}_{2}(40 \%) \\
\hline \mathrm{C}_{16} \mathrm{H}_{33} & 15 \% & \text { PSS/MA-g-C }{ }_{16} \mathrm{NH}_{2}(15 \%) \\
\cline { 2 - 3 } & 40 \% & \text { PSS/MA-g-C }{ }_{16} \mathrm{NH}_{2}(40 \%)
\end{array}
$$

Figure 1. The structure of hydrophobically modified poly(4-styrenesulfonic-co-maleic acid) copolymer (PSS/MA).

Other polyelectrolytes used for the formation of polyelectrolyte multilayer, poly(diallyldimethylammonium chloride) (PDADMAC) $(\mathrm{Mw}=100,000-200,000 \mathrm{Da})$, poly(sodium 4-styrenesulfonate, (PSS) (average $\mathrm{M}_{\mathrm{w}}=70,000 \mathrm{Da}$ ) and poly(4-styrenesulfonic-co-maleic acid) sodium salt (PSS $/ \mathrm{MA})\left(\mathrm{M}_{\mathrm{W}}=20,000 \mathrm{Da}\right)$ were obtained from Sigma-Aldrich, Poland. Water was from the Millipore Direct-Q5UV purification system $\left(18 \mathrm{M} \Omega \cdot \mathrm{cm}^{-1}\right)$. Decane was obtained from Sigma-Aldrich, Poland. To fix the solutions' ionic strength or adjust $\mathrm{pH}$, we used $\mathrm{NaCl}, \mathrm{HCl}$, and $\mathrm{NaOH}$ pure for analysis (POCh. S.A, Gliwice, Poland). 


\subsection{Surface/Interfacial Tension}

Surface tension at aqueous polymer solution/air interface or interfacial tension at the solution/decane were performed using the pendant drop shape analysis method based on fitting the solution of the Young-Laplace equation of capillarity to the shape of the pendant drop, recorded by a digital camera. The home-made experimental set-up and the fitting procedure were described in detail in [33]. The dynamic surface tension measurements were performed every $5 \mathrm{~s}$. Measured equilibrium surface tension corresponded to the one at steady-state reached after adsorption time dependent on polymer concentration. Since the studied solutions of copolymers are polydisperse concerning the molecular weight, the kinetic curves for different drops of the same solution and various batches of modified PSS/MA did often not overlap. So the experimental values are the mean values from all performed experiments (at least three drops from two batches) and the error bars represent its standard deviation. All surface tension measurements were performed at $295 \mathrm{~K}$.

\subsection{Quartz Crystal Microbalance with Dissipation (QCM-D) Measurements of the Mass of the Adsorbed Polymer}

The QCM-D technique allows analyzing mass and viscoelastic properties of films adsorbed at the surface of quartz crystal sensors. During the adsorption process, a decrease in the frequency of crystal resonance and an increase in oscillations energy dissipation is observed. An observed negative frequency shift is an indication of the mass increase due to the adsorption process. The dissipation of the crystal oscillations energy, $\Delta \mathrm{D}$, is related to the viscous losses in the film. A high value of $\Delta \mathrm{D}$ and spread for the oscillation over-tones indicates a soft film structure. If the adsorbed film is rigid, i.e., the measured dissipation is less than $1 \times 10^{-6}$ per $10 \mathrm{~Hz}$ of the frequency shift, the Sauerbrey equation describes the linear relation between the frequency shift $(\Delta f)$ and the areal mass density of the adsorbed layer $(\Delta m)[34]$ :

$$
\Delta m=-\frac{C}{\Delta f \cdot n}
$$

where $C$ is the constant of the crystal $\left(C=17.7 \mathrm{ng} / \mathrm{cm}^{2} / \mathrm{Hz}\right.$ based on the physical properties of quartz crystal) and $\mathrm{n}$ is the oscillation overtone number. This linear relation is not obeyed for soft films, and the analysis based on viscoelastic models of an adsorbed film is needed.

The formation of polyelectrolyte multilayers (PDADMAC/PSS) using the sequential adsorption method and adsorption of copolymers on top of them was observed using the QCM-D QSense E4 system (Biolin Scientific, Gothenburg, Sweden). The AT-cut, piezoelectric, gold-coated quartz sensors (14-mm diameter, $4.95-\mathrm{MHz}$ fundamental resonance frequency) (Q-Sense, Biolin Scientific, Gothenburg, Sweden) were washed with piranha solution $\left(96 \% \mathrm{H}_{2} \mathrm{SO}_{4}: 30 \% \mathrm{H}_{2} \mathrm{O}_{2}, 2: 1(v / v) ; 5 \mathrm{~min}\right)$ and then boiled in distilled water in $80{ }^{\circ} \mathrm{C}$, thoroughly rinsed with distilled water and stream-dried with air. They were then immersed in the solution of polycation (PDADMAC) for $15 \mathrm{~min}$ and rinsed in a $0.15 \mathrm{M} \mathrm{NaCl}$ solution to remove weakly adsorbed chains of polyelectrolyte from the substrate surface. Next, the substrate was immersed in the negatively charged solution (for $15 \mathrm{~min}$ ) of polyanion (PSS) and rinsed $(0.15 \mathrm{M} \mathrm{NaCl})$, which led to the formation of the polyelectrolyte bilayer. By repeating this deposition cycle, one can obtain multilayer coatings with the desired structure and thickness. In this case, that was nine layers' (PDADMAC/PSS) ${ }_{4}$ PDADMAC film. The adsorption of polyelectrolytes was conducted from the $\mathrm{NaCl}$ solution of ionic strength $0.15 \mathrm{M}$ and concentration $200 \mathrm{ppm}$. The sensor covered with polyelectrolyte film was placed in the flow cell of the QCM-D instrument. The measurement started with filling the cell with a salt solution $(0.15 \mathrm{M} \mathrm{NaCl}, \mathrm{pH}=7)$ and setting up the baseline. The temperature during the experiment was fixed at $22{ }^{\circ} \mathrm{C}$, and the flow velocity was $0.3 \mathrm{~mL} / \mathrm{min}$. A copolymer solution (concentration $200 \mathrm{ppm}$ in $0.15 \mathrm{M} \mathrm{NaCl}$ ) was introduced into the QCM-D cell. The copolymer deposition step lasted till dissipation and frequency signals achieved constant values and the cell was rinsed with salt solution $(0.15 \mathrm{M} \mathrm{NaCl}$ in $\mathrm{pH}=7)$ until again steady-state values of the frequency shift and dissipation were attained. Then the salt solution with $\mathrm{pH}=3$ was introduced to the cell for the time needed to attain steady 
frequency and dissipation shifts, followed by rinsing with the solution with $\mathrm{pH}=7$. In the second set of experiments, after rinsing with the salt solution with $\mathrm{pH}=7$, the cell was filled with the solution at $\mathrm{pH}=11$, steady frequency and dissipation shifts were attained, and the cell was rinsed again at $\mathrm{pH}=7$. The example of the crystal frequency changes during those experiments is illustrated in Figure S5 given in the Supplementary Materials. Since adsorbed layers were relatively rigid (measured dissipation was less than $1 \times 10^{-6}$ per $10 \mathrm{~Hz}$ of the frequency shift), the mass of adsorbed film was calculated with the Sauerbrey equation. The calculations were performed with Qtools 3 software (QSense, Biolin Scientific, Gothenburg, Sweden). The determined mass was the average of the results from four QCM-D cells. The experimental error was less than $10 \%$ of the measured mass. In the separate experiment, the formation of PDADMAC/PSS film was followed in the QCM-D cell to confirm its buildup. The experiment was performed according to the methodology described in [35].

\subsection{Contact Angle Analysis}

The contact angle of water droplets was determined using the Drop Shape Analyzer Krüss DSA $100 \mathrm{M}$. Water droplets with a volume of $12 \mu \mathrm{L}$ were placed at the surface of silicon wafers cleaned by washing in piranha solution and by submerging in water at $70{ }^{\circ} \mathrm{C}$ for $30 \mathrm{~min}$. The wafers were covered by the polyelectrolyte multilayer using the sequential adsorption technique described above. The adsorption of (PDADMAC/PSS) ${ }_{4}$ PDADMAC film eliminated the influence of the substrate on the contact angle of the outer layer of hydrophobically modified PSS/MA. Each deposition step took $10 \mathrm{~min}$, and after the deposition of a subsequent layer of the polymer, the sample was rinsed three times with $\mathrm{NaCl}$ solution for $1 \mathrm{~min}$. Samples terminated with hydrophobized polymers and PSS/MA were also exposed to basic conditions for $15 \mathrm{~min}$ by submerging in $\mathrm{NaCl}$ solution adjusted to $\mathrm{pH}=11$ by the addition of $\mathrm{NaOH}$. To prevent $\mathrm{NaCl}$ crystals from forming on the samples, they were rinsed three times in water for $1 \mathrm{~min}$ after the films were deposited. Then the samples were left to dry for $16 \mathrm{~h}$ in ambient air. Each measurement was the average of two runs with at least five drops. Contact angle measurements were performed at $295 \mathrm{~K}$.

Fourier transform infrared spectroscopy (FTIR) in the attenuated total reflectance (ATR) mode was for the in-situ observation of the polyelectrolyte multilayers assembly and adsorption of hydrophobically modified PSS/MA. The experiments were performed using the Thermo Scientific Nicolet iS10 (Waltham, MA, USA) FTIR spectrometer equipped with Specac 25 Reflection Variable Angle ATR accessory with Liquid Holder P/N GS 11003 flow cell. The cell was equipped with Ge crystal (25 reflections, trapezoid dimensions $52 \times 20 \times 2 \mathrm{~mm}$ ), which together with Teflon gaskets on both sides, formed two closed compartments, where adsorption of polyelectrolytes on the germanium surface took place. The polymer solution was introduced through the flow system into the liquid holder, where it was left for 15 min for the polymer to adsorb onto the crystal surface. The system was washed with $\mathrm{NaCl}$ solution, and then the FTIR spectrum was recorded. The multilayer polyelectrolyte films were formed on the crystal surface by the layer-bylayer technique by alternating adsorption of PDADMAC and PSS, and the spectrum was recorded after each deposition and rinsing step. The PSS/MA copolymer without and with grafted hydrophobic chains was adsorbed on the top of (PDADMAC/PSS) 4 PDADMAC multilayer. Since the method is very sensitive to swelling and shrinking of the polymer layers, the constant conditions were maintained during experiments-salt concentration $0.15 \mathrm{M} \mathrm{NaCl}$ and ambient temperature $\left(22^{\circ} \mathrm{C}\right)$. The spectra were acquired in the range $800-4000 \mathrm{~cm}^{-1}$ with the resolution $4 \mathrm{~cm}^{-1}$; scans were repeated 256 times and the resulting spectra were processed with PeakFit software (SeaSolve Software, San Jose, CA, USA). The background spectrum for the cell filled with $0.15 \mathrm{M} \mathrm{NaCl}$ solution was first subtracted from the ones received after the deposition of the consecutive layers of the multilayer film, the baseline established and the characteristic bands of the polyelectrolytes PDADMAC, PSS, and hydrophobized PSS/MA copolymer were identified. Bands were deconvoluted and the second derivative of the spectra was used for the decomposition of spectra into a sum of 
Gaussian and Lorentzian peaks. The differential spectra of the adsorbed polymer on top of polyelectrolyte films were determined according to the method described previously [36].

\section{Results and Discussion}

Newly synthesized hydrophobically functionalized polyelectrolytes (HF-PEs)-poly (4styrenesulfonic-co-maleic acid) (PSS/MA) with the hydrophobic side chains in their structure and the amide moiety as the linking group (PSS/MA-g- $\mathrm{C}_{\mathrm{n}} \mathrm{NH}_{2}$ ), comprise a unique set of amphiphilic polyelectrolytes (see structures in Figure 1). Therefore, the PSS/MA polyelectrolytes with $15 \%$ and $40 \%$ degree of grafting for every length of the alkyl chain were synthesized, i.e., PSS/MA-g- $\mathrm{C}_{12} \mathrm{NH}_{2}(15 \%)$, PSS/MA-g- $\mathrm{C}_{12} \mathrm{NH}_{2}(40 \%)$, PSS/MA-g$\mathrm{C}_{16} \mathrm{NH}_{2}(15 \%)$ and PSS/MA-g- $\mathrm{C}_{16} \mathrm{NH}_{2}(40 \%)$ and subjected evaluation of their adsorption properties.

\subsection{Adsorption at Fluid Interfaces}

Measurements of surface tension at air/polymer solution and interfacial tension at decane/polymer solution interfaces using the pendant drop shape analysis technique were performed to determine the adsorption properties of the hydrophobized PSS/MA copolymers (i.e., PSS / MA-g- $\mathrm{C}_{12} \mathrm{NH}_{2}$ and PSS/MA-g- $\mathrm{C}_{16} \mathrm{NH}_{2}$ ) at fluid interfaces. The dependence of surface/interfacial tension on the mass concentration of copolymers with grafted $\mathrm{C}_{12}$ and $\mathrm{C}_{16}$ alkyl chains via amide bond for $15 \%$ and $40 \%$ grafting ratio is shown in Figure 2 . The results demonstrate that unmodified PSS/MA polyelectrolyte has no surface activity up to high concentration (5000 ppm). For hydrophobized copolymers, we can observe surface activity for concentrations above $200 \mathrm{ppm}$. Interestingly, for the PSS/MA-g- $\mathrm{C}_{12} \mathrm{NH}_{2}$ we observed slightly higher surface activity (decrease of surface/interfacial tension at a lower concentration) for a lower grafting ratio (15\%), whereas, for PSS/MA-g- $\mathrm{C}_{16} \mathrm{NH}_{2}$ it seemed not to depend on the grafting ratio.

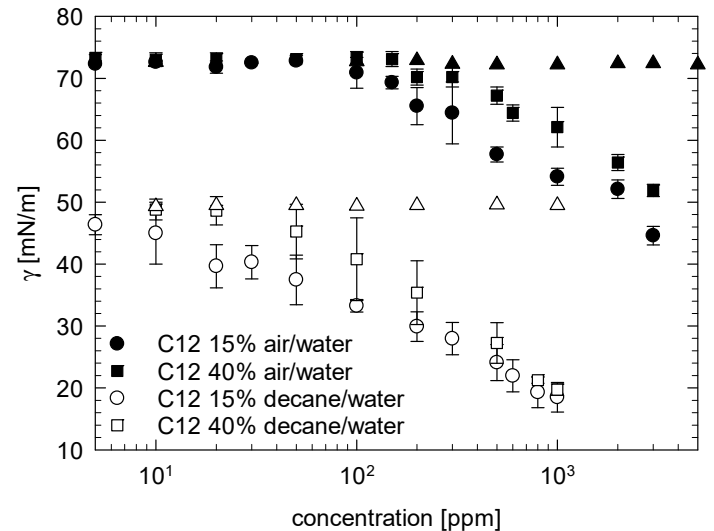

(a)

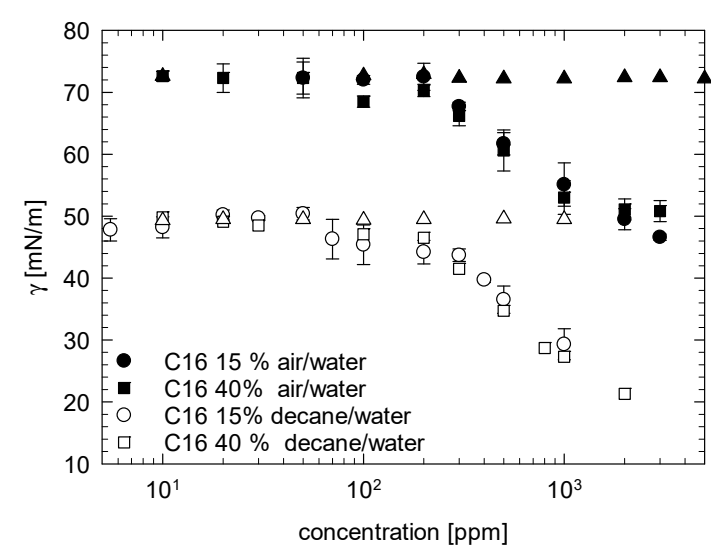

(b)

Figure 2. The dependence of the surface tension at air/solution and of interfacial tension at decane/solution interface on copolymer mass concentration. (a) For PSS/MA-g- $\mathrm{C}_{12} \mathrm{NH}_{2}$; (b) for PSS/MA-g- $\mathrm{C}_{16} \mathrm{NH}_{2}$. Triangles denote surface/interfacial tension for unmodified PSS/MA copolymer at air/water (black symbols) and decane/water (white symbols) interface, respectively.

To account for the effect of molecular weight difference, we evaluated the average $\mathrm{M}_{\mathrm{W}}$ of the synthesized copolymers taking into account the reactant used for the synthesis and the grafting degree as: 23,000 Da-PSS/MA-g- $\mathrm{C}_{12} \mathrm{NH}_{2}$ (15\%), 28,000 Da PSS/MA-g$\mathrm{C}_{12} \mathrm{NH}_{2}(40 \%), 24,000 \mathrm{Da}-\mathrm{PSS} / \mathrm{MA}-\mathrm{g}-\mathrm{C}_{16} \mathrm{NH}_{2}$ (15\%) and 31,000 Da-PSS/MA-g- $\mathrm{C}_{16} \mathrm{NH}_{2}$ $(40 \%)$. We used the average $\mathrm{M}_{\mathrm{W}}$ to express surface/interfacial tension isotherms as molar concentration dependence. The results are given in Figure 3. Contrary to the expectation, the surface activity for the PSS/MA-g- $\mathrm{C}_{12} \mathrm{NH}_{2}$ copolymer was again slightly higher for the lower grafting ratio while for the PSS/MA-g- $\mathrm{C}_{16} \mathrm{NH}_{2}$ no differences in surface activity were observed. 


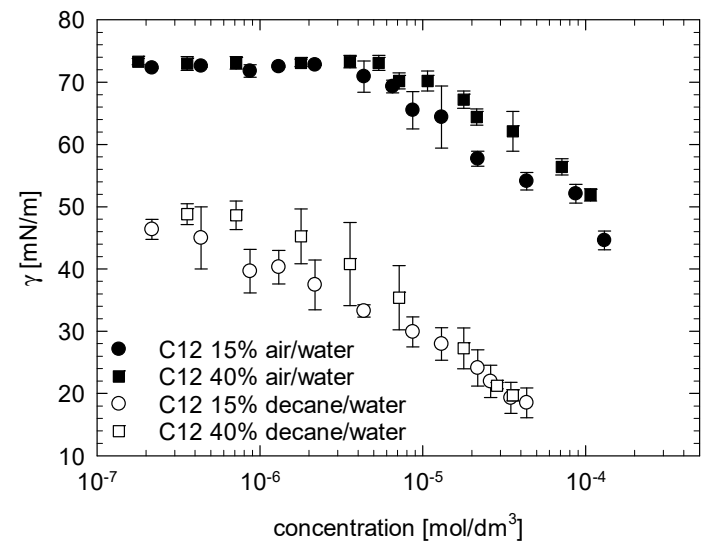

(a)

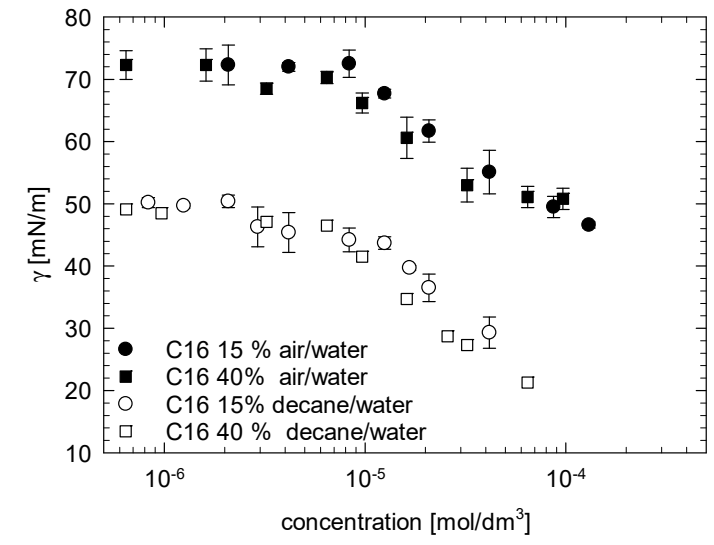

(b)

Figure 3. The dependence of the surface tension at air/solution and interfacial tension at the decane/solution interface on copolymer molar concentration. (a) For PSS/MA-g- $\mathrm{C}_{12} \mathrm{NH}_{2}$; (b) for PSS/MA-g- $\mathrm{C}_{16} \mathrm{NH}_{2}$.

In our previous papers $[6,20]$, we demonstrated that the hydrophobic domains are formed consisting of two to three hydrophobic chains collapsed onto the polyelectrolyte backbone. With increasing grafting density, these domains can merge and the polyelectrolyte molecule can assume the form of a pseudo-micelle. For the polymer to be adsorbed at the air/water or oil/water interface, those micelles need to re-conform with the alkyl chains exposed to the hydrophobic phase. That re-conformation can be less favorable for PSS/MA-g- $\mathrm{C}_{12} \mathrm{NH}_{2}(40 \%)$ than for PSS/MA-g- $\mathrm{C}_{12} \mathrm{NH}_{2}$ (15\%). On the other hand, the re-conformation tendency is the same for PSS/MA-g- $\mathrm{C}_{16} \mathrm{NH}_{2}$ disregarding the alkyl chain grafting density, however, lower than for PSS/MA-g- $\mathrm{C}_{12} \mathrm{NH}_{2}$ taking into account smaller surface activity (c.f. Figure 3a,b). That result is consistent with one obtained by Théodoly et al., who studied the adsorption of hydrophobic polyelectrolyte, polystyrene with various degrees of sulphonation, at the air/water interface [37]. They found that such polyelectrolyte's surface activity first increased with the charged fraction, reached an optimum at $55 \%$, and then decreased. They explained the presence of optimum of adsorption with the degree of sulfonation by a conformational barrier effect, more hydrophobic chains assuming the compact shape of a charged colloid that prevented adsorption. Similarly, Barazza et al. studied the adsorption of hydrophobically modified polyelectrolytes at the n-octane/water interface. They concluded that the free energy of adsorption could be split into contributions arising from two different processes, namely, the distribution of the polymer between the bulk of the solution and the arrangement of the macromolecule at the interface [38].

The addition of electrolyte increased surface activity of hydrophobized PSS/MA polyelectrolyte; however, that effect was much more pronounced at the decane/solution interface, as it is demonstrated in Figure 4, where the surface/interfacial tension isotherms in water and $0.15 \mathrm{M} \mathrm{NaCl}$ for PSS/MA-g-C ${ }_{16} \mathrm{NH}_{2}(15 \%)$ and PSS/MA-g- $\mathrm{C}_{16} \mathrm{NH}_{2}(40 \%)$ are compared. Similar results were obtained for PSS/MA-g- $\mathrm{C}_{12} \mathrm{NH}_{2}(15 \%)$ and PSS/MA-g$\mathrm{C}_{12} \mathrm{NH}_{2}(40 \%)$ (not shown). The addition of $0.1 \mathrm{M} \mathrm{NaOH}$ to the copolymer solution had a small effect on surface activity (except for small concentration) due to the compensation of two effects, screening of ionic charges due to the higher ionic strength of the solution and higher charge of the polymer caused by the deprotonation of carboxylic groups at high $\mathrm{pH}$.

\subsection{Adsorption at Solid Surface Covered with Polyelectrolyte Multilayer}

To analyze the adsorption properties of the hydrophobized PSS/MA copolymers, PSS/MA-g- ${ }_{12} \mathrm{NH}_{2}(15 \%)$, PSS/MA-g- $\mathrm{C}_{12} \mathrm{NH}_{2}(40 \%)$, PSS/MA-g- $\mathrm{C}_{16} \mathrm{NH}_{2}(15 \%)$, and PSS/MA-g- $\mathrm{C}_{16} \mathrm{NH}_{2}(40 \%)$, we determined the mass of adsorbed polymer on top of the (PDADMAC/PSS) 4 PDADMAC multilayer, deposited on top of the QCM sensor as described in the "Materials and Methods" section. Then we determined the response of 
the deposited film and its stability while exposed to acidic $(\mathrm{pH}=3)$ and basic $(\mathrm{pH}=11)$ conditions. The results are collected in Table 1.

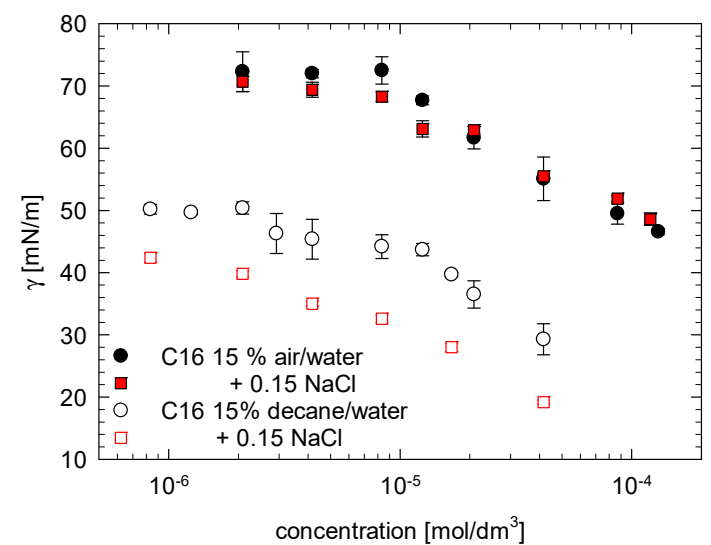

(a)

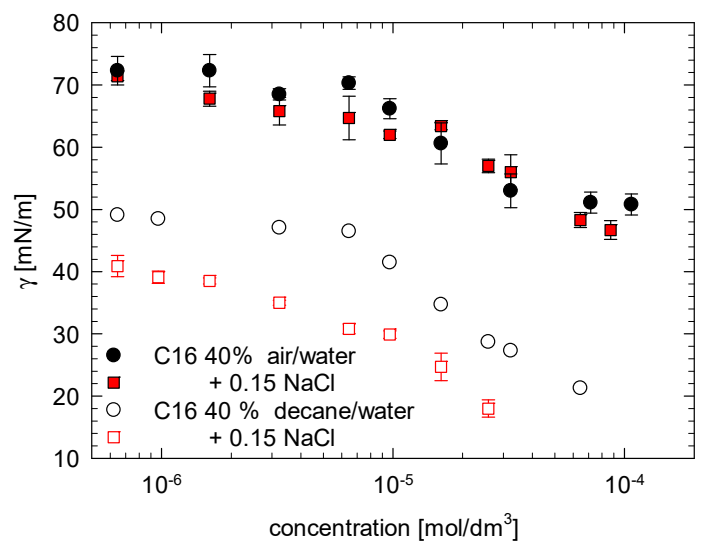

(b)

Figure 4. The dependence of the surface tension at air/solution and of interfacial tension at the decane/solution interface on copolymer molar concentration in water and $0.15 \mathrm{NaCl}$. (a) For PSS/MA-g- $\mathrm{C}_{16} \mathrm{NH}_{2}$ (15\%); (b) for PSS/MA-g-C 16 NH 2 $(40 \%)$.

Table 1. Mass of copolymer deposited on top of (PDADMAC/PSS) ${ }_{4} \mathrm{PDADMAC}$ multilayer film.

\begin{tabular}{|c|c|c|c|c|c|}
\hline \multirow[b]{2}{*}{ Copolymer } & \multirow{2}{*}{$\begin{array}{c}\text { Mass of } \\
\text { Copolymer } \\
\left(\mathrm{ng} / \mathrm{cm}^{2}\right) \mathrm{pH}=7\end{array}$} & \multicolumn{4}{|c|}{ Film Mass Increment with Respect to Deposited at $\mathrm{pH}=7\left(\mathrm{ng} / \mathrm{cm}^{2}\right)$} \\
\hline & & $\mathrm{pH}=3$ & $\begin{array}{c}\mathrm{pH}=7 \text { Rinsing } \\
\text { after } \mathrm{pH}=3\end{array}$ & $\mathrm{pH}=11$ & $\begin{array}{c}\mathrm{pH}=7 \text { Rinsing } \\
\text { after } \mathrm{pH}=\mathbf{1 1}\end{array}$ \\
\hline $\mathrm{PSS} / \mathrm{MA}$ & 247 & -210 & -19 & +75 & -60 \\
\hline PSS/MA-g-C ${ }_{12} \mathrm{NH}_{2}(15 \%)$ & 217 & -125 & +46 & +75 & +34 \\
\hline PSS/MA-g- $\mathrm{C}_{12} \mathrm{NH}_{2}(40 \%)$ & 219 & -150 & +27 & +47 & -30 \\
\hline PSS/MA-g-C $16 \mathrm{NH}_{2}(15 \%)$ & 227 & -135 & +52 & +22 & -7 \\
\hline PSS/MA-g- $\mathrm{C}_{16} \mathrm{NH}_{2}(40 \%)$ & 193 & -160 & +30 & +13 & +9 \\
\hline
\end{tabular}

Adsorption of the PSS/MA-g- $\mathrm{C}_{n} \mathrm{NH}_{2}$ on positively charged polyelectrolyte film terminated by the PDADMAC layer appeared to be slightly less effective than that of the non-modified copolymer. Upon exposure to acidic conditions, $\mathrm{pH}=3$, the mass of the films largely decreased, but for films covered with the hydrophobically modified copolymer, it was regained. Since the process is mostly reversible, it can be attributed to a decrease in film hydration. Carboxylic groups of maleic acid become protonated, the negative charge decreases and the excess of compensating counterions are repelled from the film together with hydrating water. After exposure to basic conditions, $\mathrm{pH}=11$, the opposite phenomenon could be observed, carboxylic groups become fully deprotonated, negative charge increases, and the film swells. Measured film mass increased and then grew upon rinsing at $\mathrm{pH}=7$. The coating of the polyelectrolyte film with hydrophobically modified PSS/MA seemed to stabilize the whole multilayer structure.

We determined the effect of the external layer of a polyelectrolyte multilayer film formed with the hydrophobically modified PSS/MA copolymer on its wettability. For that purpose, we deposited (PDADMAC/PSS) 4 PDADMAC on a silicon wafer and then adsorbed the copolymer by deep coating in $200 \mathrm{ppm}$ aqueous solution in $0.15 \mathrm{NaCl}$. We determined the equilibrium contact angle by the sessile drop method. The results are collected in Table 2.

We noted the typical dependence of the contact angle observed for the polyelectrolyte multilayers, i.e., the structure with a polycation (PDADMAC) in the top layer being more hydrophobic than one with a polyanion (PSS or PSS/MA) [39,40]. Surfaces covered with hydrophobically modified PSS/MA were slightly more hydrophobic than ones with unmodified PSS/MA at the top layer and the contact angle increased with the length of the 
alkyl chain grafted at the polyelectrolyte backbone. That limited increase of hydrophobicity and lower adsorption of PSS/MA-g- $\mathrm{C}_{\mathrm{n}} \mathrm{NH}_{2}$ can be the evidence that the modified polyelectrolyte is adsorbed preferably in the form of pseudo-micelles; thus, alkyl chains can be less exposed to the aqueous phase. We observed an increase of the contact angle when the films were exposed to basic conditions $(\mathrm{pH}=11)$ for $15 \mathrm{~min}$ (c.f. Table 2) except for the PEM with PSS/MA-g- $\mathrm{C}_{16} \mathrm{NH}_{2}$ as a top layer. As it was demonstrated in Table 1, the film swells due to hydration, polycation chains become more mobile and can penetrate the top layer of the film, which increases its hydrophobicity. Since the swelling is the lowest for PSS/MA-g- $\mathrm{C}_{16} \mathrm{NH}_{2}$ the increase of hydrophobicity was not observed. The decrease of the contact angle at the film terminated by the PDADMAC layer upon exposure to $\mathrm{pH}=11$ seems to confirm that hypothesis as the top layer can be penetrated by more mobile polyanions.

Table 2. The equilibrium contact angle of water drop at silicon wafer surface coated with the polyelectrolyte multilayer.

\begin{tabular}{cccccccc}
\hline $\begin{array}{c}\text { Polymer at the } \\
\text { Top Layer }\end{array}$ & PSS & PDADMAC & PSS/MA & $\begin{array}{c}\text { PSS/MA-g- } \\
\mathbf{C}_{\mathbf{1 2}} \mathbf{N H}_{\mathbf{2}} \\
\mathbf{( 1 5 \% )}\end{array}$ & $\begin{array}{c}\text { PSS/MA-g- } \\
\mathbf{C}_{\mathbf{1 2}} \mathbf{N H}_{\mathbf{2}} \\
\mathbf{4 0 \%}\end{array}$ & $\begin{array}{c}\text { PSS/MA-g- } \\
\mathbf{C}_{\mathbf{1 6}} \mathbf{N H}_{\mathbf{2}} \\
\mathbf{( 1 5 \% )}\end{array}$ & $\begin{array}{c}\text { PSS/MA-g- } \\
\mathbf{C}_{\mathbf{1 6}} \mathbf{N H}_{\mathbf{2}} \\
\mathbf{( 4 0 \% )}\end{array}$ \\
\hline $\begin{array}{c}\text { Contact angle } \\
\text { (deg) }\end{array}$ & $14 \pm 4$ & $35 \pm 8$ & $15 \pm 4$ & $18 \pm 3$ & $16 \pm 3$ & $24 \pm 2$ & $21 \pm 5$ \\
$\begin{array}{c}\text { Contact angle after } \\
\text { pH = 11 (deg) }\end{array}$ & - & $23 \pm 4$ & $23 \pm 5$ & $29 \pm 4$ & $23 \pm 6$ & $25 \pm 5$ & $23 \pm 6$ \\
\hline
\end{tabular}

We applied the FTIR-ATR technique to investigate the formation of the polyelectrolyte multilayer and adsorption of the hydrophobically modified PSS/MA as its external layer. Application of that technique allowed to monitor changes of IR spectra of films and interfacial water due to the increased hydrophobicity of the copolymers. The example of the IR spectra obtained at the consecutive steps of the formation of (PDADMAC/PSS) ${ }_{4}$ PDADMAC multilayer film on the surface of Ge crystal, followed by the adsorption of unmodified PSS/MA, is illustrated in Figure 5a.

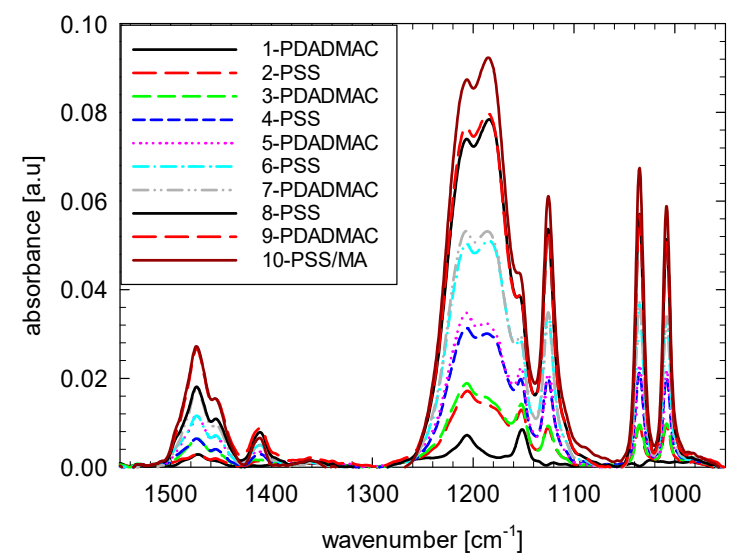

(a)

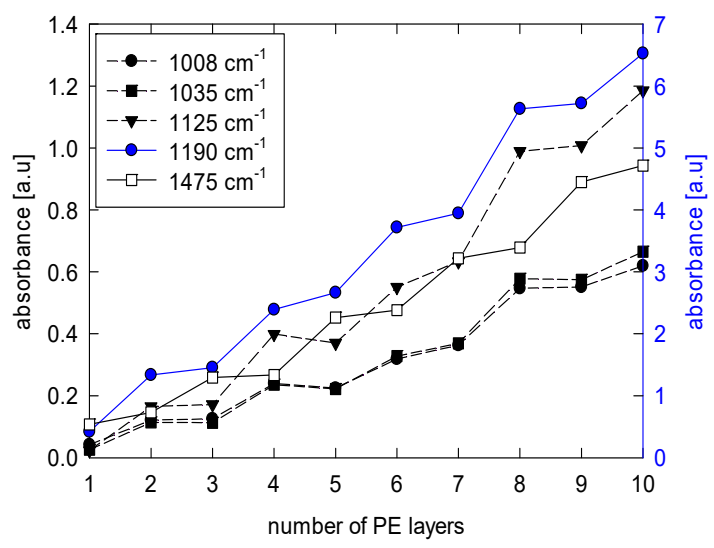

(b)

Figure 5. (a) An example of the FTIR spectra obtained at the consecutive steps of the formation of (PDADMAC/PSS) 4 PDADMAC multilayer film on the surface of Ge crystal, followed by the adsorption of unmodified PSS/MA; (b) changes in the intensity of the fingerprint bands of PSS and PDADMAC upon the formation of the multilayer film.

Several fingerprint bands for PSS and PDADMAC can be clearly identified. At 1008, 1035,1125 , and $1190 \mathrm{~cm}^{-1}$, respectively, the in-plane bending vibrations of the parasubstituted benzene ring, symmetric and asymmetric stretching vibration of the $\mathrm{SO}_{3}{ }^{-}$ group for PSS, and $1475 \mathrm{~cm}^{-1}$ the vibration of the amine group of PDADMAC [41]. Upon adsorption of consecutive layers of the film, the intensity of those fingerprint bands in- 
creases with the characteristic odd-even effect (odd layers-PDADMAC, even layers-PSS), but the overall growth of the film is linear, as it is illustrated in Figure 5b. That correlates well with the results of previous studies of PDADMAC/PSS multilayer film formation by the QCM-D [35] (see also Figure S6). The adsorption of PSS/MA was confirmed by an increase in PSS characteristic bands' intensity, while the intensity characteristic bands for the carboxylic groups were too weak to be identified and partly overlap with the band at $1475 \mathrm{~cm}^{-1}$. Table 3 presents the intensity differences of these bands upon adsorption of PSS/MA copolymers (non-modified or hydrophobically modified) on top of (PDADMAC/PSS) ${ }_{4}$ PDADMAC multilayer film (see Figure S7). These results confirm that the adsorption is not dependent on the hydrophobicity of the copolymer.

Table 3. The intensity difference of the PSS characteristic bands for adsorbed non-modified and modified PSS/MA copolymer as the top layer of the multilayer film.

\begin{tabular}{cccccc}
\hline & \multicolumn{5}{c}{ Intensity Difference of PSS Characteristic Bands (a.u) } \\
\hline Adsorbed Copolymer & $\mathbf{1 0 0 8} \mathbf{~ m}^{-\mathbf{1}}$ & $\mathbf{1 0 3 5} \mathbf{~ c m}^{-\mathbf{1}}$ & $\mathbf{1 1 2 5} \mathbf{~ c m}^{-\mathbf{1}}$ & $\mathbf{1 1 9 0} \mathbf{~ c m}^{-\mathbf{1}}$ & Sum \\
\hline PSS/MA & 0.08 & 0.12 & 0.24 & 0.71 & 1.15 \\
PSS/MA-g-C ${ }_{2} \mathrm{NH}_{2}(15 \%)$ & 0.13 & 0.17 & 0.27 & 0.87 & 1.44 \\
PSS/MA-g-C $12 \mathrm{NH}_{2}(40 \%)$ & 0.06 & 0.03 & 0.33 & 1.08 & 1.50 \\
\hline
\end{tabular}

The ATR analysis of the changes of IR spectra of the water $v_{\mathrm{OH}}$ stretching band in the region between 3000 and $3800 \mathrm{~cm}^{-1}$ allows determining a variation of water structure at the interface upon adsorption of the consecutive polyelectrolyte layers [42,43]. The infrared spectrum of water in that region contains four components that can be ranked by hydrogen bonding strength. These components at approximately $3280,3440,3550$, and $3630 \mathrm{~cm}^{-1}$ correspond to water from that which is most hydrogen-bonded with its surroundings to water that is least hydrogen-bonded [42,44]. Figure 6 demonstrates the differential spectra of the multilayer film after adsorption of top polycation layer (PDADMAC/PSS) 2 PDADMAC, (PDADMAC/PSS $)_{3}$ PDADMAC, (PDADMAC/PSS ${ }_{4}$ PDADMAC, adsorption of the polyanion (PDADMAC/PSS) ${ }_{3},(\text { PDADMAC/PSS })_{4}$ and non-functionalized and hydrophobized PSS/MA. These results suggest that upon adsorption of polycation (PDADMAC), the intensity of all water $v_{\mathrm{OH}}$ stretching bands is uniformly reduced. On the other hand, when polyanion is adsorbed on top of the polyelectrolyte film, the intensity of bands associated with strong hydrogen bonding is mostly decreased. Moreover, the hydrophobization degree of PSS/MA copolymer has a strong effect on the water structure. Upon adsorption of hydrophobized polyanion, the intensity of water bands associated with weak hydrogen bonding becomes reduced stronger with a higher degree of the alkyl chain grafting. Correlating those findings with the contact angle measurements we can conclude that hydrophobization of the surface of polyelectrolyte film, either by adsorption of polycation or hydrophobized polyanion, leads to reduction of water irrespective of its hydrogen bonds with the underlying polymer layer, while adsorption of more hydrophilic polyanion mostly eliminates water with strong hydrogen bonds. That result may correlate with the finding of Ho et al., who applied ATR-FTIR and showed that water in the multilayer is subject to noticeably less hydrogen bonding than water in the bulk [43].

We investigated the IR spectra of PEMs with the hydrophobically modified PSS/MA as their external layer when exposed to alkaline conditions, $\mathrm{pH}=11$. The example of the spectrum changes for PSS/MA-g- $\mathrm{C}_{12} \mathrm{NH}_{2}(15 \%)$ is illustrated in Figure 7 . Immediately after the film was exposed to the alkaline environment, bands of carboxylic ion appeared at $1580-1565 \mathrm{~cm}^{-1}$ and around $1410 \mathrm{~cm}^{-1}$ and the weak band at $1710 \mathrm{~cm}^{-1}$ attributed to a protonated carboxylic group diminished [45]. Similar results were obtained for unmodified PSS/MA and PSS/MA-g- $\mathrm{C}_{12} \mathrm{NH}_{2}(40 \%)$, as illustrated in Figure S8. We did not observe any significant changes in the spectra obtained after exposure to $\mathrm{pH}=11$ for up to two hours and flushing back with the solution with $\mathrm{pH}=7$. That indicates that within that time frame films were stable, and we did not observe base-catalyzed hydrolysis of the amide bond; 
however, that aspect requires further investigation, including more extended exposure to alkaline conditions and taking spectra in $\mathrm{D}_{2} \mathrm{O}$ to avoid overlapping of the amid and water bands.

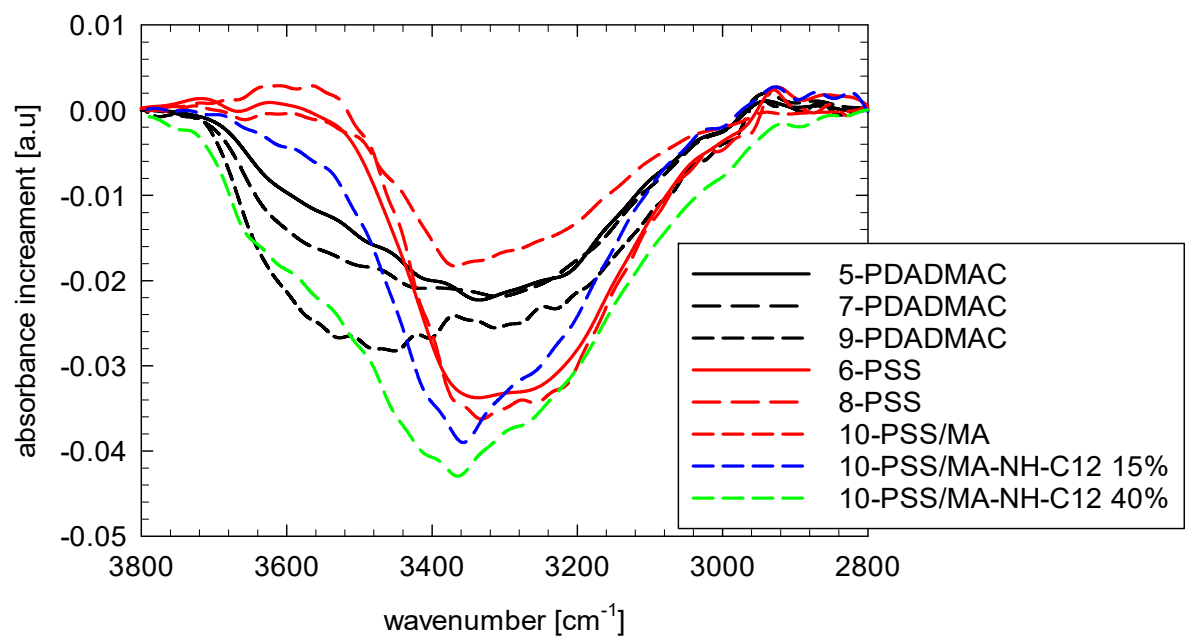

Figure 6. The differential spectra of adsorbed polyelectrolyte layers in the range of the water $v_{\mathrm{OH}}$ stretching band.

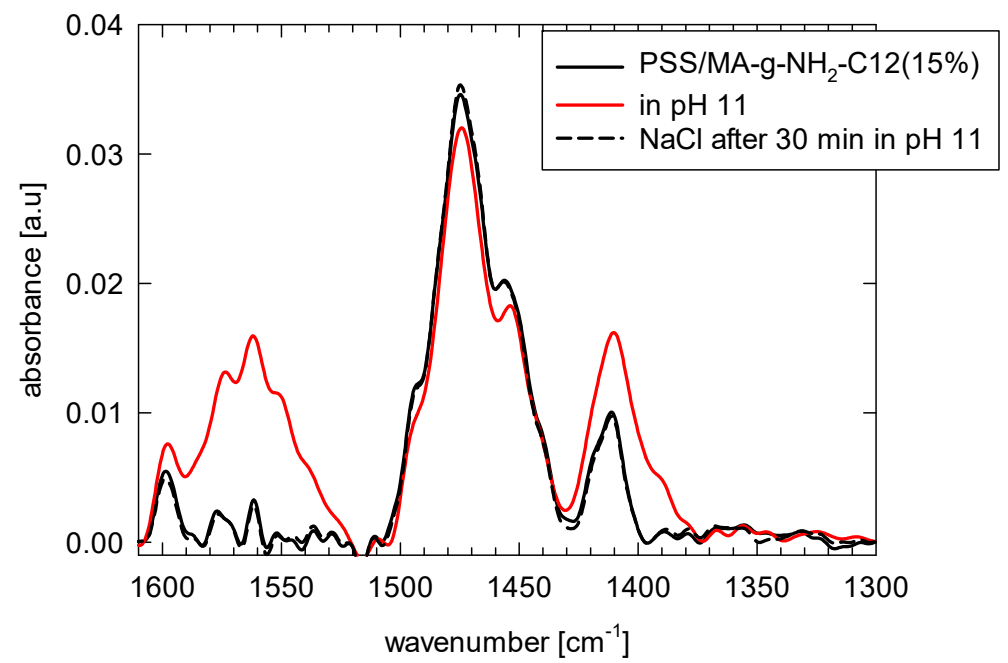

Figure 7. The example of the FTIR spectra of (PDADMAC/PSS) 4 PDADMAC multilayer film with adsorbed PSS/MA-g- $\mathrm{C}_{12} \mathrm{NH}_{2}(15 \%)$ as the last layer during the exposure to the alkaline environment $\mathrm{pH}=11$. The dashed line illustrates the spectrum obtained after exposure for $30 \mathrm{~min}$ at $\mathrm{pH}=11$ and flushing with $0.15 \mathrm{M} \mathrm{NaCl}$ solution $\mathrm{pH}=7$.

\section{Conclusions}

The rationally designed hydrophobically functionalized poly(4-styrenesulfonic-comaleic acid) derivatives (i.e., PSS $/ \mathrm{MA}-\mathrm{g}-\mathrm{C}_{\mathrm{n}} \mathrm{NH}_{2} ; \mathrm{n}=12,16$ ) -with both strongly (sulfonic) and weakly (carboxylate) acidic moieties as well as having the side $C_{12}$ and $C_{16}$ chains attached to the PE backbone via the amide linker-made it possible to achieve a distinct group of amphiphilic pH-responsible PEs. Considering their soft (chemodegradable, hydrolyzable) structure, they can be treated as one of the custom-designed products. Our present studies made it possible to receive some crucial information about their structure influence, mainly of the grafting density and the hydrophobic chain length, on adsorption phenomena at the fluid interfaces and solid surface covered with polyelectrolyte multilayers. All newly synthesized HF-PEs were surface active in contrast with non-functionalized PSS/MA 
polyanion; however, the tendency to self-aggregation can affect surface activity at fluid interfaces. Therefore, some optimal grafting density can be expected.

We found that PSS/MA-g- $\mathrm{C}_{\mathrm{n}} \mathrm{NH}_{2}(\mathrm{n}=12,16$, the grafting ratio $=15 \%, 40 \%)$ form satisfactorily stable films at the surface of PEM with the top polycationic layer. The results of the quartz crystal microbalance with dissipation (QCM-D), Fourier transform infrared spectroscopy in the attenuated total reflectance mode (FTIR-ATR) experiments and contact angle analysis revealed the efficacious ability of the studied PSS/MA-g- $\mathrm{C}_{\mathrm{n}} \mathrm{NH}_{2}$, to adsorb at the PEMs. In contrast to non-modified PSS/MA, coating of the film with hydrophobically modified polyelectrolyte increased its stability for exposure to the mildly acidic and basic medium. Our FTIR-ATR experiments revealed the changes in water structure upon the adsorption of the layers of PEMs. Adsorption of polycation led to a uniform reduction of all water $v_{\mathrm{OH}}$ stretching bands, while when polyanion was adsorbed on top of the polyelectrolyte film, the intensity of bands associated with strong hydrogen bonding was mostly decreased. Moreover, upon adsorption of hydrophobized polyanion, the intensity of water bands associated with weak hydrogen bonding becomes also reduced and the decrease was more pronounced for a higher degree of the alkyl chain grafting. Thus, the modification of polyelectrolyte film's surface, either by adsorption of polycation or hydrophobically modified polyanion, leads to a removal of water irrespective of its hydrogen bonding with the underlying polymer layer. In contrast, adsorption of more hydrophilic polyanion mostly eliminates preferably water with strong hydrogen bonds.

Our findings allow concluding that the unique characteristics of hydrophobically modified PSS/MA may open the possibility of understanding its further performance properties, especially toward $\mathrm{pH}$ triggering structures for drug delivery. They can be successfully applied either as efficacious emulsifiers for the formation of (nano)emulsions for further active substance encapsulation using the sequential adsorption method or as one of the convenient building blocks for the surface modification materials.

Supplementary Materials: The following are available online at https:/ / www.mdpi.com/2504-5 $377 / 5 / 1 / 3 / s 1$, Details of synthesis of hydrophobically functionalized poly(4-styrenosulfonic-comaleic acid), Figure S1: Synthetic routes for hydrophobically functionalized poly(4-styrenosulfonicco-maleic acid); Figure S2. 1H NMR spectra of the non-functionalized PSS/MA (0-8 ppm range); Figure S3. ${ }^{1} \mathrm{H}$ NMR spectra of the synthesized hydrophobically functionalized poly(4-styrenosulfonicco-maleic acid) with amide linking group (0-8 ppm range); Figure S4. 1H NMR spectra of the synthesized hydrophobically functionalized poly(4-styrenosulfonic-co-maleic acid) with amide linking group (0.5-3.5 ppm and 5.5-8.0 ppm ranges); Figure S5: The example of the QCM-D data obtained by monitoring the deposition of the copolymer (PSSMA-g- $\mathrm{C}_{12} \mathrm{NH}_{2}(40 \%)$ ) on top of the multilayer film. A-changes in the frequency during copolymer deposition on top of the (PDADMAC/PSS) 4 PDADMAC films and rinsing solution of $0.15 \mathrm{M} \mathrm{NaCl}$ in $\mathrm{pH}=7$ and $\mathrm{pH}=11$. B-changes in the frequency during copolymer deposition on top of the (PDADMAC/PSS $)_{4,5}$ films and rinsing solution of $0.15 \mathrm{M} \mathrm{NaCl}$ in $\mathrm{pH}=7$ and $\mathrm{pH}=3$. Spikes observed at c.a. $850 \mathrm{~s}$ are artifacts, disregarded in the analysis; Figure S6: The example of the QCM-D data obtained by monitoring the formation of the (PDADMAC/PSS) ${ }_{4}$ PDADMAC multilayer film and the respective increase of the film's mass; Figure S7: The FTiR spectra in the PSS fingerprint region for (PDADMAC/PSS) ${ }_{4}$ PDADMAC film without (dashed line) and with adsorbed copolymer layer (solid line): A. PSS/MA; B. PSS/MA-g-C ${ }_{12} \mathrm{NH}_{2}$ (15\%); C. PSS/MA-g- $\mathrm{C}_{12} \mathrm{NH}_{2}$ (40\%); Figure S8. The FTIR spectra of (PDADMAC/PSS) ${ }_{4}$ PDADMAC multilayer film with adsorbed copolymer as the last layer during the exposure to the alkaline environment $\mathrm{pH}=11$. The dashed line illustrates the spectrum obtained after exposure for $30 \mathrm{~min}$ at $\mathrm{pH}=11$ and flushing with $0.15 \mathrm{M} \mathrm{NaCl}$ solution $\mathrm{pH}=7$. Top-PSS/MA, bottom-PSS/MA-g- $\mathrm{C}_{12} \mathrm{NH}_{2}(40 \%)$.

Author Contributions: Conceptualization, P.W. and K.A.W.; methodology, E.J., Z.K.-K., T.K.; Ł.L., S.R.; formal analysis, E.J., Z.K.-K., and T.K.; investigation, E.J., Z.K.-K., T.K.; Ł.L., S.R.; writing—original draft preparation, P.W.; writing-review and editing, P.W., K.A.W., Ł.L., E.J.; visualization, E.J., T.K., Z.K.-K.; supervision, P.W., and K.A.W. All authors have read and agreed to the published version of the manuscript. 
Funding: This work has been supported by the National Science Center Poland within a framework of the OPUS programme (2017/25/B/ST4/02450).

Data Availability Statement: The data if not directly presented in this study are available on request from the corresponding author.

Acknowledgments: The authors thank Eng. Marzena Noworyta for her skillful help in the surface tension experiments.

Conflicts of Interest: The authors declare no conflict of interest.

\section{References}

1. Kötz, J.; Kosmella, S.; Beitz, T. Self-assembled polyelectrolyte systems. Prog. Polym. Sci. 2001, 26, 1199-1232. [CrossRef]

2. Olea, A.F. Hydrophobic Polyelectrolytes. In Ionic Interactions in Natural and Synthetic Macromolecules; John Wiley \& Sons, Inc.: Hoboken, NJ, USA, 2012; pp. 211-233. ISBN 9780470529270.

3. Seantier, B.; Deratani, A. Polyelectrolytes at Interfaces: Applications and Transport Properties of Polyelectrolyte Multilayers in Membranes. In Ionic Interactions in Natural and Synthetic Macromolecules; John Wiley \& Sons, Inc.: Hoboken, NJ, USA, 2012; pp. 683-726. ISBN 9780470529270.

4. Lamch, Ł.; Pucek, A.; Kulbacka, J.; Chudy, M.; Jastrzębska, E.; Tokarska, K.; Bułka, M.; Brzózka, Z.; Wilk, K.A. Recent progress in the engineering of multifunctional colloidal nanoparticles for enhanced photodynamic therapy and bioimaging. Adv. Colloid Interface Sci. 2018, 261, 62-81. [CrossRef] [PubMed]

5. Stuart, M.A.C.; Huck, W.T.S.; Genzer, J.; Müller, M.; Ober, C.; Stamm, M.; Sukhorukov, G.B.; Szleifer, I.; Tsukruk, V.V.; Urban, M.; et al. Emerging applications of stimuli-responsive polymer materials. Nat. Mater. 2010, 9, 101-113. [CrossRef] [PubMed]

6. Lamch, Ł.; Ronka, S.; Warszyński, P.; Wilk, K.A. NMR studies of self-organization behavior of hydrophobically functionalized poly(4-styrenosulfonic-co-maleic acid) in aqueous solution. J. Mol. Liq. 2020, 308, 112990. [CrossRef]

7. Decher, G.; Schlenoff, J.B. (Eds.) Multilayer Thin Films; Wiley-VCH Verlag GmbH \& Co. KGaA: Weinheim, Germany, 2012; Volumes 1-2, ISBN 9783527646746.

8. Sukhorukov, G.B.; Donath, E.; Lichtenfeld, H.; Knippel, E.; Knippel, M.; Budde, A.; Möhwald, H. Layer-by-layer self assembly of polyelectrolytes on colloidal particles. Colloids Surfaces Physicochem. Eng. Asp. 1998, 137, 253-266. [CrossRef]

9. Szczepanowicz, K.; Hoel, H.J.; Szyk-Warszynska, L.; Bielańska, E.; Bouzga, A.M.; Gaudernack, G.; Simon, C.; Warszynski, P. Formation of Biocompatible Nanocapsules with Emulsion Core and Pegylated Shell by Polyelectrolyte Multilayer Adsorption. Langmuir 2010, 26, 12592-12597. [CrossRef]

10. Picart, C.; Caruso, F.; Voegel, J.-C. (Eds.) Layer-by-Layer Films for Biomedical Applications; Wiley-VCH Verlag GmbH \& Co. KGaA: Weinheim, Germany, 2015; ISBN 9783527675869.

11. Richardson, J.J.; Bjornmalm, M.; Caruso, F. Technology-driven layer-by-layer assembly of nanofilms. Science 2015, 348 , aaa2491. [CrossRef]

12. Antipov, A.A.; Sukhorukov, G.B. Polyelectrolyte multilayer capsules as vehicles with tunable permeability. Adv. Colloid Interface Sci. 2004, 111, 49-61. [CrossRef]

13. Tsirigotis-Maniecka, M.; Szyk-Warszyńska, L.; Lamch, Ł.; Weżgowiec, J.; Warszyński, P.; Wilk, K.A. Benefits of pH-responsive polyelectrolyte coatings for carboxymethyl cellulose-based microparticles in the controlled release of esculin. Mater. Sci. Eng. C 2021, 118, 111397. [CrossRef]

14. Sadman, K.; Wang, Q.; Chen, Y.; Keshavarz, B.; Jiang, Z.; Shull, K.R. Influence of Hydrophobicity on Polyelectrolyte Complexation. Macromolecules 2017, 50, 9417-9426. [CrossRef]

15. Leermakers, F.A.M.; Léonforte, F.; Luengo, G.S. Structure and Colloidal Stability of Adsorption Layers of Macrocycle, Linear, Comb, Star, and Dendritic Macromolecules. Macromolecules 2020, 53, 7322-7334. [CrossRef]

16. Borisov, O.V.; Halperin, A. Self-assembly of polysoaps. Curr. Opin. Colloid Interface Sci. 1998, 3, 415-421. [CrossRef]

17. Borisov, O.V.; Halperin, A. Micelles of Polysoaps. Langmuir 1995, 11, 2911-2919. [CrossRef]

18. Morishima, Y.; Kobayashi, T.; Nozakura, S. Amphiphilic Polyelectrolytes with Various Hydrophobic Groups: Intramolecular Hydrophobic Aggregation in Aqueous Solution. Polym. J. 1989, 21, 267-274. [CrossRef]

19. Dobrynin, A.V.; Rubinstein, M. Hydrophobically Modified Polyelectrolytes in Dilute Salt-Free Solutions. Macromolecules 2000, 33, 8097-8105. [CrossRef]

20. Lamch, Ł.; Ronka, S.; Moszyńska, I.; Warszyński, P.; Wilk, K.A. Hydrophobically Functionalized Poly(Acrylic Acid) Comprising the Ester-Type Labile Spacer: Synthesis and Self-Organization in Water. Polymers 2020, 12, 1185. [CrossRef]

21. Huang, J.; Morin, F.J.; Laaser, J.E. Charge-Density-Dominated Phase Behavior and Viscoelasticity of Polyelectrolyte Complex Coacervates. Macromolecules 2019, 52, 4957-4967. [CrossRef]

22. Biswas, A.; Cheng, H.N.; Kim, S.; Alves, C.R.; Furtado, R.F. Hydrophobic Modification of Cashew Gum with Alkenyl Succinic Anhydride. Polymers 2020, 12, 514. [CrossRef]

23. Poujol, S.; Pinguet, F.; Bressole, F.; Boustta, M.; Vert, M. Molecular Microencapsulation: Paclitaxel Formations in Aqueous Medium Using Hydrophobized Poly(L-Lysine Citramide Imide). J. Bioact. Compat. Polym. 2000, 15, 99-114. [CrossRef] 
24. Domurado, D.; Vert, M. Bioresorbable polyelectrolyte amphiphiles as nanosized carriers for lipophilic drug solubilization and delivery. J. Biomater. Sci. Polym. Ed. 2007, 18, 287-301. [CrossRef]

25. Locatelli-Champagne, C.; Suau, J.-M.; Guerret, O.; Pellet, C.; Cloitre, M. Versatile Encapsulation Technology Based on Tailored pH-Responsive Amphiphilic Polymers: Emulsion Gels and Capsules. Langmuir 2017, 33, 14020-14028. [CrossRef] [PubMed]

26. Szczepanowicz, K.; Bazylińska, U.; Pietkiewicz, J.; Szyk-Warszyńska, L.; Wilk, K.A.; Warszyński, P. Biocompatible long-sustained release oil-core polyelectrolyte nanocarriers: From controlling physical state and stability to biological impact. Adv. Colloid Interface Sci. 2015, 222, 678-691. [CrossRef] [PubMed]

27. Tjipto, E.; Quinn, J.F.; Caruso, F. Assembly of Multilayer Films from Polyelectrolytes Containing Weak and Strong Acid Moieties. Langmuir 2005, 21, 8785-8792. [CrossRef]

28. Gong, X. Controlling surface properties of polyelectrolyte multilayers by assembly pH. Phys. Chem. Chem. Phys. 2013, 15, 10459. [CrossRef] [PubMed]

29. Zhang, X.; Zhang, Q.; Ma, T.; Liu, Q.; Wu, S.; Hua, K.; Zhang, C.; Chen, M.; Cui, Y. Enhanced Stability of Gold Magnetic Nanoparticles with Poly(4-styrenesulfonic acid-co-maleic acid): Tailored Optical Properties for Protein Detection. Nanoscale Res. Lett. 2017, 12, 547. [CrossRef] [PubMed]

30. Su, P.-G.; Cheng, K.-H. Self-assembly of polyelectrolytic multilayer thin films of polyelectrolytes on quartz crystal microbalance for detecting low humidity. Sens. Actuators B Chem. 2009, 142, 123-129. [CrossRef]

31. Maza, E.; Tuninetti, J.S.; Politakos, N.; Knoll, W.; Moya, S.; Azzaroni, O. pH-responsive ion transport in polyelectrolyte multilayers of poly(diallyldimethylammonium chloride) (PDADMAC) and poly(4-styrenesulfonic acid-co-maleic acid) (PSS-MA) bearing strong- and weak anionic groups. Phys. Chem. Chem. Phys. 2015, 17, 29935-29948. [CrossRef]

32. Magny, B.; Iliopoulos, I.; Audebert, R.; Piculell, L.; Lindman, B. Interactions between hydrophobically modified polymers and surfactants. In Trends in Colloid and Interface Science VI; Steinkopff: Darmstadt, Germany, 2007; pp. 118-121.

33. Para, G.; Jarek, E.; Warszynski, P. The Hofmeister series effect in adsorption of cationic surfactants-Theoretical description and experimental results. Adv. Colloid Interface Sci. 2006, 122, 39-55. [CrossRef]

34. Bruckenstein, S.; Shay, M. Experimental aspects of use of the quartz crystal microbalance in solution. Electrochim. Acta 1985, 30, 1295-1300. [CrossRef]

35. Elżbieciak-Wodka, M.; Kolasińska-Sojka, M.; Nowak, P.; Warszyński, P. Comparison of permeability of poly(allylamine hydrochloride)/and poly(diallyldimethylammonium chloride)/poly(4-styrenesulfonate) multilayer films: Linear vs. exponential growth. $J$. Electroanal. Chem. 2015, 738, 195-202. [CrossRef]

36. Szyk-Warszyńska, L.; Raszka, K.; Warszyński, P. Interactions of Casein and Polypeptides in Multilayer Films Studied by FTIR and Molecular Dynamics. Polymers 2019, 11, 920. [CrossRef]

37. Théodoly, O.; Ober, R.; Williams, C.E. Adsorption of hydrophobic polyelectrolytes at the air/water interface: Conformational effect and history dependence. Eur. Phys. J. E 2001, 5, 51-58. [CrossRef]

38. Barraza, R.G.; Olea, A.F.; Martinez, F.; Ruiz-Tagle, I. Adsorption of hydrophobically modified polyelectrolytes at the -octane/water interface. J. Colloid Interface Sci. 2003, 261, 559-564. [CrossRef]

39. Kolasińska, M.; Warszyński, P. The effect of nature of polyions and treatment after deposition on wetting characteristics of polyelectrolyte multilayers. Appl. Surf. Sci. 2005, 252, 759-765. [CrossRef]

40. Elzbieciak, M.; Kolasinska, M.; Warszynski, P. Characteristics of polyelectrolyte multilayers: The effect of polyion charge on thickness and wetting properties. Colloids Surfaces A Physicochem. Eng. Asp. 2008, 321, 258-261. [CrossRef]

41. Gregoriou, V.G.; Hapanowicz, R.; Clark, S.L.; Hammond, P.T. Infrared Studies of Novel Optically Responsive Materials: Orientation Characteristics of Sulfonated Polystyrene/Poly(Diallyldimethylammonium Chloride) Ionic Polymer Multilayers on Patterned Self-Assembled Monolayers. Appl. Spectrosc. 1997, 51, 470-476. [CrossRef]

42. Thouvenin, M.; Linossier, I.; Sire, O.; Péron, J.-J.; Vallée-Réhel, K. Structural and Dynamic Approach of Early Hydration Steps in Erodable Polymers by ATR-FTIR and Fluorescence Spectroscopies. Macromolecules 2002, 35, 489-498. [CrossRef]

43. Ho, T.T.M.; Bremmell, K.E.; Krasowska, M.; MacWilliams, S.V.; Richard, C.J.E.; Stringer, D.N.; Beattie, D.A. In Situ ATR FTIR Spectroscopic Study of the Formation and Hydration of a Fucoidan/Chitosan Polyelectrolyte Multilayer. Langmuir 2015, 31, 11249-11259. [CrossRef]

44. Lasagabaster, A.; Abad, M.J.; Barral, L.; Ares, A. FTIR study on the nature of water sorbed in polypropylene (PP)/ethylene alcohol vinyl (EVOH) films. Eur. Polym. J. 2006, 42, 3121-3132. [CrossRef]

45. Rivas, B.L.; Seguel, G.V.; Geckeler, K.E. Synthesis, characterization, and properties of polychelates of poly(styrene sulfonic acid-co-maleic acid) with Co(II), Cu(II), Ni(II), and Zn(II). J. Appl. Polym. Sci. 2002, 85, 2546-2551. [CrossRef] 